\title{
Modeling and optimization of surface roughness and tool vibration in CNC turning of Aluminum alloy using hybrid RSM-WPCA methodology
}

\author{
Priyabrata Sahoo $^{a^{*}}$, Ashwani Pratap ${ }^{\mathrm{b}}$ and Asish Bandyopadhyay \\ ${ }^{a, c}$ Mechanical Engineering Department, Jadavpur University, Kolkata, India, 700032 \\ ${ }^{b}$ Mechanical Engineering Department, Indian Institute of Technology Patna, India, 801103

\section{CH R O N I C L E}

\begin{tabular}{l} 
Article history: \\
Received October 202016 \\
Received in Revised Format \\
October 282016 \\
Accepted November 242016 \\
Available online \\
November 252016 \\
\hline Keywords: \\
CNC turning \\
Surface roughness \\
Tool vibration \\
RSM \\
WPCA \\
ANOVA
\end{tabular}

\section{Introduction}

Turning is one of the primitive and widely applicable machining processes. To cope with minimum cost and flexibility in machining process, automation to the conventional turning process has been adopted. In general, the machining study emphasizes on work material composition and its mechanical properties, cutting tool properties and all the input parameter settings that influence output quality characteristics as well as process efficiency. Process efficiency can be significantly improved by optimization of process parameters which identifies the zone of critical process parameter leading to desired responses by ensuring low cost of production (Montgomery, 1997). Aluminum and its alloys have been widely used in biomedical, pharmaceutical, food processing, health care, automotive and space research industries for various applications. They exhibit strong, light weight, higher ductility as well as excellent oxidation and

* Corresponding author

E-mail: sahoopriyabrata89@gmail.com (P. Sahoo)

(C) 2017 Growing Science Ltd. All rights reserved. doi: $10.5267 /$ j.jiiec.2016.11.003

\begin{abstract}
This paper suggests an advanced hybrid multi output optimization technique by applying weighted principal component analysis (WPCA) incorporated with response surface methodology (RSM). This investigation has been carried out through a case study in CNC turning of Aluminum alloy 63400 for surface roughness $(\mathrm{Ra})$ and tool vibration $(\mathrm{db})$ optimization. Primarily, input parameters such as spindle speed (N), feed rate (S) and depth of alloy workpieces are machined by using coated carbide tool (inserts) in dry environment. Secondly, the empirical model for the responses as the functions of cutting parameters are

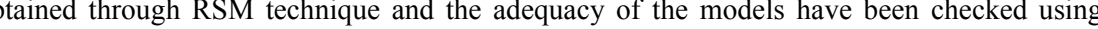
analysis of variance (ANOVA). Finally, the process parameters are optimized using WPCA technique. The confirmatory experiment has been performed using optimized result and it reveals setting. The increases in MPI value indicates that the aforesaid optimization methodology is suitably acceptable for multi response optimization for turning process.
\end{abstract}


corrosion resistance. However, machining of aluminium is associated with some difficulties due to its softness. Due to the soft and sticky nature of aluminium, specific geometries and characteristics of carbide inserts are generally used for efficient machining and to avoid built up edge formation (Roy et al., 2009).

Surface roughness has a viable importance in machining process as it is regarded as a measure of quality index of a product (Wang et al., 2010). It measures the closely spaced irregularities smaller than waviness in the surface texture. However, achieving a desired surface finish is a major issue with respect to functional behaviour of a machined part. The production cost and performance of machined parts are greatly influenced by surface finish as it affects various factors such as friction, geometrical tolerance, ease of holding, transition fit, thermal and electrical conductivity and many more (Makadia \& Nanavati, 2013). In turning process, the surface finish is influenced by various parameters such as feed rate, depth of cut, cutting speed, nose radius of cutting tool, cutting environment, tool wear, machine vibrations, mechanical and material properties of work material and tool. A small deviation in any of the aforementioned parameters may affect the machined surface significantly (Knight \& Boothroyd, 2005). The un-avoidable dynamic interactions between the cutting tool and work piece cause vibration and hence the chatter noise. This chatter has adverse effect on various parameters including surface roughness, dimensional accuracy, tool wear, etc. (Siddhupura \& Paurobally, 2012). According to Tobias (1961), mechanical vibration in turning process is classified into three categories viz. natural, force and self-excited. These vibrations mainly occur due to the lack of rigidity of the machine tool. Among them, self-excited vibration or chatter is the most harmful and uncontrollable because of its complex nature. Therefore, there is a need to analyze and optimize such responses which has adverse effect on machining process to make the process more efficient and cost effective. Although, process modelling and optimization is not a new approach, still complicacy persists in modelling of surface roughness and vibration as these responses are affected by various parameters up to different ranges. Various modelling, optimization and simulation approaches have been adopted by researchers for optimization of surface roughness and vibration so far.

Palanikumar (2010) carried out statistical modelling using RSM to investigate the effect of process parameters on surface roughness and delamination factor in turning operation of glass fiber reinforced composite. RSM central composite design matrix was employed for the experiment. The adequacy of the model was verified at $95 \%$ confidence level within limit of input parameters being considered. Asilturk and Naseli (2012) conducted multi objective optimization along with empirical models for surface roughness parameters optimization with respect to cutting parameters (cutting speed, feed rate, depth of cut) in CNC turning of AISI 304 stainless steel. It was observed from the analysis that feed was the most significant factor influencing surface roughness. Gupta et al. (2011) applied Taguchi-Fuzzy multi response optimisation for output responses like surface roughness, power consumption, cutting force and tool life with respect to cutting parameters along with cutting conditions (dry, wet, cryogenic) and nose radius in $\mathrm{CNC}$ turning of tool steel. They fuzzified the signal to noise ratio $(\mathrm{S} / \mathrm{N})$ of output parameters to make comprehensive output measure $(\mathrm{COM})$ which was being used as response for single objective optimization.

Surface roughness not only varies according to cutting parameters but also with the progress of tool wear. So, a signal which presents the interaction effect between cutting tool and workpiece should be studied when surface roughness is the main concern. Kirby et al. (2004) developed a mathematical model in terms of feed rate and vibration signal along cutting, feed and thrust direction during investigation on surface roughness. Risbood et al. (2003) developed a prediction equation using ANN taking radial vibration of tool holder as a feedback signal. Rudrapati et al. (2016) studied the effect of process parameters of cylindrical grinding process on the responses like workpiece vibration and surface roughness using RSM methodology. Process parameters were optimized for the desired responses using multi objective genetic algorithm and predicted model was verified using confirmatory test. Routara et 
al. (2010) attempted a new multi response optimization for cylindrical grinding parameters by incorporating Taguchi philosophy with weighted principal component analysis (WPCA).

Most of the optimization methods are associated with some assumptions, conflicts and constraints. Usual conflict faced by the researchers is the implementation of weightage to find out the optimal settings. From the literature, it is evident that optimization problems neglect the correlation of responses but this is not valid in real application for all cases.

To meet such challenges, a new hybrid optimization technique has been implemented in the present work. The study has been carried out experimentally. Data analysis and modelling has been attempted using RSM and ANOVA. Effect of process parameters (spindle speed, feed rate, depth of cut) on responses such as surface roughness and tool vibration has been analyzed using 3-D contour plot. Optimization of the output responses for evaluating the best combinations of input parameters has been carried out by using WPCA technique. In this method the co-related responses are converted into uncorrelated indices termed as principal components considering accountability proportion (AP) value as weightage. Finally the individual principal components have been merged to get a single composite principal component regarded as multi response performance index (MPI). MPI values have been utilised as index for single objective optimization.

\section{Analysis and optimisation methodology}

\subsection{Response Surface Methodology (RSM)}

RSM is a collection of statistical and empirical methods which is very useful for developing, improving, and optimizing processes parameters (Phadke, 1995). RSM is extensively used in the situation where various input variables significantly influence some output responses or quality index of the process. Sometimes the input variables are also called independent variables. RSM is mostly used to analyze the influence of input parameters on the specific responses (Routara et al., 2012). This method can also be used to define the contribution of the independent variables (input parameters) on the desired responses (output parameters). The vital purpose of developing regression models is to co-relate the responses with the independent variables which lead to optimization of the process parameters. Commonly used mathematical model for the response y and independent variables $\xi_{1}, \xi_{2} \ldots \xi_{\mathrm{k}}$ can be represented as

$$
y=f\left(\xi_{1}, \xi_{2}, \ldots, \xi_{k}\right)+\varepsilon
$$

where, $\varepsilon$ is termed as a statistical error, which is normally distributed by response y with mean zero and variance $\sigma^{2}$. Then,

$$
E(y)=\eta=E\left[f\left(\xi_{1}, \xi_{2}, \ldots, \xi_{k}\right)\right]+E(\varepsilon)=f\left(\xi_{1}, \xi_{2}, \ldots, \xi_{k}\right) .
$$

The variables $\xi_{1}, \xi_{2}, \ldots$, $\xi_{\mathrm{k}}$ in Eq. (2) are called as natural variables, as they are expressed in the natural units of measurement. However it is more convenient to use coded variables $\left(x_{1}, x_{2}, x_{3} \ldots\right)$ which are dimensionless. The response function $(\eta)$ can be written as

$$
\eta=f\left(x_{1}, x_{2}, \ldots, x_{k}\right) \text {. }
$$

It is evident from the literature that second orders mathematical model is mostly used due to flexibility, wide variety of functional forms and use of significant least square method. Second order quadratic model can be expressed as

$$
\eta=\beta_{0}+\sum_{j=1}^{k} \beta_{j} x_{j}+\sum_{j=1}^{k} \beta_{j j} x_{j}^{2}+\sum_{i<} \sum_{j=2}^{k} \beta_{i j} x_{i} x_{j},
$$

where, $\beta_{\mathrm{j}} \mathrm{s}$ are regression coefficient and $\mathrm{x}_{\mathrm{j}} \mathrm{s}$ are coded form of independent variables. 


\subsection{Weighted Principal Component Analysis (WPCA)}

To optimize the multi response objective, Su and Tong (1997) proposed a new method called as principal component analysis. Approach of this method is preceded through different steps (1) normalization of each response, (2) Checking of co-relation between different normalized responses, (3) conversion of the normalized responses to un-correlated index regarded as principal components (Liao, 2006). The principal components are calculated as

$$
\mathrm{P}_{\mathrm{j}}=\sum_{i=1}^{r} a_{j i} Y_{i}, \text { for } \mathrm{j}=1, \ldots \ldots, \mathrm{k}
$$

where, $Y_{i}$ is the normalized value of $\mathrm{i}^{\text {th }}$ responses $(\mathrm{i}=1,2, \ldots ., \mathrm{r})$. For computation of PCA, $\mathrm{k}(\mathrm{k} \leq \mathrm{r})$ number of components can be obtained for the explanation of variance of the responses. The coefficient $a_{j i}$ is termed as eigen vector, where $\sum_{i=1}^{r} a_{j i}^{2}=1$. The selected principal component is used as an index to optimize the multi response problem. However, two shortcomings are related with PCA method. First, if the principal component value is greater than one and second, as the principal components are explained by total variation, multi response performance index can't be replaced by multi response solutions. In order to overcome these challenges, weighted principal component analysis (WPCA) is incorporated (Datta et al., 2009). As each principal component has its own variance which may not be same, in this study variance of every principal component is used as the weight to compute multi response performance index (MPI). MPI can be calculated as

$$
\mathrm{MPI}=\sum_{j=1}^{k} W_{j} P_{j}
$$

where, $W_{j}$ is regarded as weight of the corresponding principal component. MPI value defines the response for the single objective optimization and it is regarded as the quality index. Hence, greater is the MPI value, more is the quality.

\section{Experimental Details}

\subsection{Design of Experiment (DOE)}

Under the umbrella of DOE, most of the researchers design their experimental plans to reduce time and resources without compromising with quality. The result obtained from such experiments is quite easy to analyze as the experimental errors are minimized (Rudrapati et al., 2016). In this study, RSM BoxBehnken design has been applied for experimentation considering three levels of the three input parameters $(\mathrm{N}, \mathrm{S}, \mathrm{t})$. The input machining parameters and their levels are shown in Table 1. The experimental design matrix developed by Box-Behnken design is given in Table 2. It represents all combinations of factors consisting of twelve points at the centre of the edge of the face of the cube and one point at centre of the cube with three replications. Total 15 numbers of combinations are formulated for the experimentation.

\section{Table 1}

Levels of process parameters

\begin{tabular}{cccc}
\hline Coded levels & $\begin{array}{c}\text { Spindle speed, } \mathrm{N} \\
(\mathrm{rpm})\end{array}$ & $\begin{array}{c}\text { Feed rate, S } \\
(\mathrm{mm} / \mathrm{min})\end{array}$ & $\begin{array}{c}\text { Depth of cut, } \mathrm{t} \\
(\mathrm{mm})\end{array}$ \\
\hline-1 & 600 & 25.0 & 0.2 \\
0 & 650 & 37.5 & 0.3 \\
+1 & 700 & 50.0 & 0.4 \\
\hline
\end{tabular}


Table 2

Experimental design matrix

\begin{tabular}{ccccccc}
\hline $\begin{array}{c}\text { Standard } \\
\text { order }\end{array}$ & \multicolumn{2}{c}{ Spindle speed $(\mathrm{N})$} & \multicolumn{2}{c}{ Feed rate $(\mathrm{S})$} & \multicolumn{2}{c}{ Depth of Cut $(\mathrm{t})$} \\
\cline { 2 - 6 } & Code $(\mathrm{A})$ & $\begin{array}{c}\text { Actual } \\
(\mathrm{rpm})\end{array}$ & Code $(\mathrm{B})$ & $\begin{array}{c}\text { Actual } \\
(\mathrm{mm} / \mathrm{min})\end{array}$ & $\begin{array}{c}\text { Code } \\
(\mathrm{C})\end{array}$ & $\begin{array}{c}\text { Actual } \\
(\mathrm{mm})\end{array}$ \\
\hline 1 & -1 & 600 & 0 & 37.5 & +1 & 0.4 \\
2 & 0 & 650 & 0 & 37.5 & 0 & 0.3 \\
3 & -1 & 600 & 0 & 37.5 & -1 & 0.2 \\
4 & -1 & 600 & +1 & 50.0 & 0 & 0.3 \\
5 & 0 & 650 & -1 & 25.0 & +1 & 0.4 \\
6 & +1 & 700 & +1 & 50.0 & 0 & 0.3 \\
7 & +1 & 700 & -1 & 25.0 & 0 & 0.3 \\
8 & 0 & 650 & +1 & 50.0 & -1 & 0.2 \\
9 & 0 & 650 & +1 & 50.0 & +1 & 0.4 \\
10 & -1 & 600 & -1 & 25.0 & 0 & 0.3 \\
11 & 0 & 650 & -1 & 25.0 & -1 & 0.2 \\
12 & 0 & 650 & 0 & 37.5 & 0 & 0.3 \\
13 & +1 & 700 & 0 & 37.5 & -1 & 0.2 \\
14 & +1 & 700 & 0 & 37.5 & +1 & 0.4 \\
15 & 0 & 650 & 0 & 37.5 & 0 & 0.3 \\
\hline
\end{tabular}

\subsection{Machine and material}

The machine tool used for this experiment is a HMT CNC lathe having FANUC control system. The CNC lathe is equipped with $3200 \mathrm{RPM}$ maximum spindle speed, $1-699 \mathrm{~mm} / \mathrm{min}$ feed rate and $0.3 \mathrm{KW}$ output power. For generation of machined surface, CNC part programmes have been created using Gcodes. For the better performance in machining, CVD coated tool are used in the experiments. The tool used for machining is K-10, WIDIA inserts having hardness $1570 \mathrm{HV}$, density $14.5 \mathrm{~g} / \mathrm{cc}$, transverse rupture strength $3800 \mathrm{~N} / \mathrm{mm}^{2}$ and tool specifications: $-6^{\circ}--6^{\circ}-11^{\circ}-8^{\circ}-36^{\circ}-90^{\circ}-0.8(\mathrm{~mm})$. The experiments are carried out on 15 numbers of same composition aluminum alloys bar having dimension $\Phi 22 \times 60$ $\mathrm{mm}$ (Fig. 1). The mechanical properties of the work piece specimen are as follows: hardness: $124 \mathrm{HV}$, ultimate tensile strength: $1.8-26 \mathrm{kgf} / \mathrm{mm}^{2}$, melting Point: $660^{\circ} \mathrm{C}$, density: $2600-2800 \mathrm{~kg} / \mathrm{mm}^{3}$ and its chemical composition is $\mathrm{Cu}-0.01 \%, \mathrm{Mg}-0.64 \%$, Si- $0.70 \%$, Fe- $0.17 \%$, Mn- $0.11 \%$, Zn- $0.06 \%$, Ti- $0.03 \%$, Cr- $0.01 \%$, remaining Al.

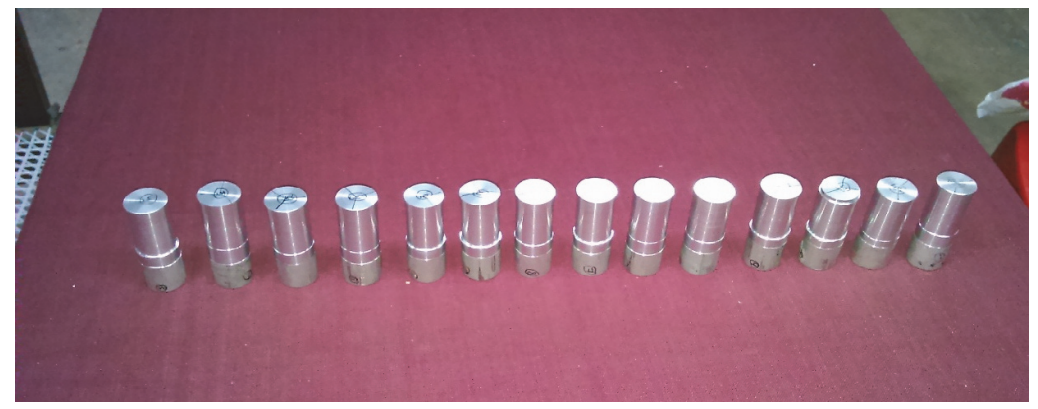

Fig. 1. Photographic view of machined workpieces

\subsection{Vibration and Roughness Measurement}

Tool vibration has been measured online during machining by placing uniaxial piezoelectric accelerometer (Make: syscon Instrument Pvt. Ltd., Bangalore, Model: 353b31) on the tool holder, as shown in Fig. 2. The output of the accelerometer is fed to the digital real-time oscilloscope with FFT 
module (Make: Tektronix, Model: TDS 2MM), which gives the mechanical signal in terms of electrical signal. From literature (Feng, 2001), it is evident that amplitude parameter of vibration has significant effect on tool vibration so the amplitude parameter $(\mathrm{db})$ is selected as a response. Root mean square (RMS) value of the amplitude parameter has been calculated which is used as vibration response. Initially, trial run are carried out by placing the accelerometer in radial (X), axial (Z) and cutting (Y) directions to observe the significant effect of tool vibration. Initial run reveals that tool vibration has significant effect in Z-direction, therefore vibration data in Z-direction has been acquired for the case study. Surface roughness measurement is carried out by using contact type stylus profilometer Talysurf (Make:Taylor Hobson, Surtronic 3+, UK). The photographic view of the profilometer set up is shown in Fig. 3. Profilometer is equipped with a diamond stylus of $5 \mu \mathrm{m}$ tip radius. The arithmetic average amplitude parameter $\left(\mathrm{R}_{\mathrm{a}}\right)$ is widely used in industry; the same parameter has been considered in this study. Roughness of each specimen is measured thrice and average values of the calculated $R_{a}$ values are recorded. Obtained results from tool vibration and surface roughness measurements are shown in Table 3.

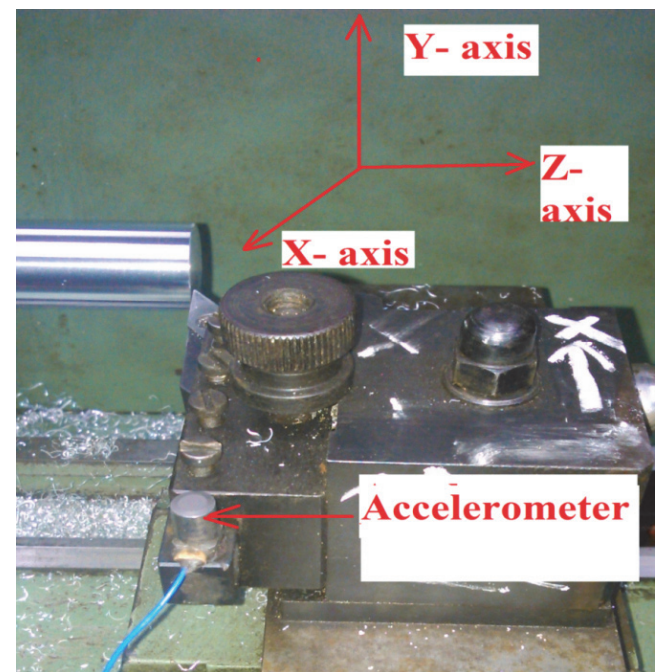

Fig. 2. Photographic view of position of accelerometer on tool holder

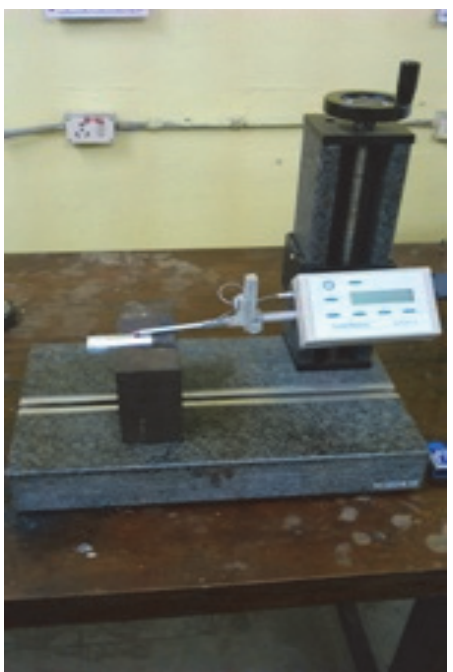

Fig. 3. Photographic view of stylus type profilometer, Talysurf

Table 3

Experimental data of surface roughness (Ra) and tool vibrations (V) corresponding to Box-Behnken design of experiment

\begin{tabular}{|c|c|c|c|c|c|}
\hline \multirow[t]{2}{*}{ Experiment No. } & \multicolumn{3}{|c|}{ Process parameters } & \multicolumn{2}{|c|}{ Observed values } \\
\hline & $\begin{array}{l}\text { Spindle speed } \\
\text { (rpm) }\end{array}$ & $\begin{array}{l}\text { Feed rate } \\
(\mathrm{mm} / \mathrm{min})\end{array}$ & $\begin{array}{l}\text { Depth of cut } \\
(\mathrm{mm})\end{array}$ & $\begin{array}{c}\text { Surface } \\
\text { Roughness, } \\
\mathrm{R}_{\mathrm{a}}(\mu \mathrm{m})\end{array}$ & $\begin{array}{c}\text { Vibration } \\
\text { amplitude } \\
\text { V (db) }\end{array}$ \\
\hline 1 & 600 & 37.5 & 0.4 & 0.749 & 74.506 \\
\hline 2 & 650 & 37.5 & 0.3 & 0.905 & 81.304 \\
\hline 3 & 600 & 37.5 & 0.2 & 0.704 & 73.2626 \\
\hline 4 & 600 & 50.0 & 0.3 & 1.167 & 78.156 \\
\hline 5 & 650 & 25.0 & 0.4 & 0.653 & 78.904 \\
\hline 6 & 700 & 50.0 & 0.3 & 1.163 & 79.811 \\
\hline 7 & 700 & 25.0 & 0.3 & 0.589 & 77.986 \\
\hline 8 & 650 & 50.0 & 0.2 & 1.168 & 79.798 \\
\hline 9 & 650 & 50.0 & 0.4 & 1.200 & 83.440 \\
\hline 10 & 600 & 25.0 & 0.3 & 0.596 & 69.580 \\
\hline 11 & 650 & 25.0 & 0.2 & 0.592 & 76.947 \\
\hline 12 & 650 & 37.5 & 0.3 & 0.893 & 81.579 \\
\hline 13 & 700 & 37.5 & 0.2 & 0.682 & 74.409 \\
\hline 14 & 700 & 37.5 & 0.4 & 0.723 & 76.703 \\
\hline 15 & 650 & 37.5 & 0.3 & 0.886 & 81.597 \\
\hline
\end{tabular}




\section{Results and Analysis}

To analyze the measured responses for the input parameters, checking for adequacy of the model is essential. The model adequacy can be checked by incorporating verification of regression model, model coefficient, and lack of fit value (Senthilkumar, 2014). To satisfy all these purposes, ANOVA is the appropriate choice and the same has been applied in this study. To find out the best combination of input parameters for better surface finish and less vibration, a multi output optimisation technique is also performed.

\subsection{Analysis of Surface Roughness and Tool Vibration}

The main purpose of data analysis is to find the significant individual and interaction effects of independent variables on the dependent responses (Rudrapati et al., 2016). ANOVA analysis has been performed using the software package Design Expert 7.0. There is various type of regression model such as linear, quadratic, interaction. Quadratic model is chosen for both surface roughness and tool vibration as it is recommended by fit summary. The results of the ANOVA analysis are presented in Table 4 (Surface Roughness) and Table.5 (Tool Vibration). The value of $\mathrm{R}^{2}$ for both surface roughness and tool vibration are more than $90 \%$, which reveals that the model has very good correlation with the experimental data. The adjusted $\mathrm{R}^{2}$ value for surface roughness and vibration are $99.84 \%$ and $89.41 \%$ which indicates good correlation. Both of the Surface roughness model and Vibration model are statically significant as p-values are less than 0.05 , considering $95 \%$ confidence level. For surface roughness, lack of fit term is not significant which is desirable; however in case of vibration, lack of fit is significant. Therefore further investigation is necessary for tool vibration analysis. From Table 4, it can be concluded that individual effect of feed rate $(\mathrm{S})$ is most significant for surface roughness as it has the highest $\mathrm{F}$ value (Lowest $\mathrm{P}$ value). Along with the feed rate, the individual effect of spindle speed $(\mathrm{N})$, depth of cut (t) and the second order effect of spindle speed $\left(\mathrm{N}^{2}\right)$, feed rate $\left(\mathrm{S}^{2}\right)$ and depth of cut $\left(\mathrm{t}^{2}\right)$ are significant terms for the model as the corresponding p-values are less than 0.05 . The interaction effect of spindle speed-feed rate $(\mathrm{N}-\mathrm{S})$, spindle speed-depth of cut $(\mathrm{N}-\mathrm{t})$ and feed rate-depth of cut $(\mathrm{S}-\mathrm{t})$ are not found to be significant as $p$ values of the terms are less than 0.05. ANOVA analysis for tool vibration is presented in Table 5. From Table 5, it revealed that second order term of spindle speed $\left(\mathrm{N}^{2}\right)$ has the highest significance in the model for tool vibration as it is having lowest $p$-value. Apart from this, individual effect of spindle speed $(\mathrm{N})$, feed rate $(\mathrm{S})$, depth of cut $(\mathrm{t})$, second order effect of depth of cut $\left(\mathrm{t}^{2}\right)$ and interaction effect of spindle speed-depth of cut $(\mathrm{N}-\mathrm{t})$ are significant terms for this model. Rest of the terms are not significant. Although, for both the cases models are statistically significant but to improve the performance of the models, non significant terms are eliminated.

Table 4

ANOVA table for surface roughness

\begin{tabular}{|c|c|c|c|c|c|}
\hline Source & DOF & Sum Square & Mean square & F-value & P-value \\
\hline Model & 9 & 0.74 & 0.082 & 974.92 & $<0.0001$ significant \\
\hline $\mathrm{N}$ & 1 & $4.351 \mathrm{E}-004$ & 4.351E-004 & 5.15 & 0.0725 \\
\hline $\mathrm{S}$ & 1 & 0.64 & 0.64 & 7610.71 & $<0.0001$ \\
\hline $\mathrm{T}$ & 1 & $4.005 \mathrm{E}-003$ & $4.005 \mathrm{E}-003$ & 47.41 & 0.0010 \\
\hline $\mathrm{N}^{2}$ & 1 & 0.039 & 0.039 & 457.68 & $<0.0001$ \\
\hline$S^{2}$ & 1 & 0.028 & 0.028 & 326.38 & $<0.0001$ \\
\hline$t^{2}$ & 1 & 0.022 & 0.022 & 264.76 & $<0.0001$ \\
\hline $\mathrm{N} * \mathrm{~S}$ & 1 & $2.250 \mathrm{E}-006$ & $2.250 \mathrm{E}-006$ & 0.027 & 0.8768 \\
\hline $\mathrm{N} * \mathrm{t}$ & 1 & $4.000 \mathrm{E}-006$ & $4.000 \mathrm{E}-006$ & 0.047 & 0.8363 \\
\hline $\mathrm{S} * \mathrm{t}$ & 1 & 2.102E-004 & $2.102 \mathrm{E}-004$ & 2.49 & 0.1755 \\
\hline Res. error & 5 & 4.224E-004 & $8.448 \mathrm{E}-005$ & - & - \\
\hline Lack of fit & 3 & $2.377 \mathrm{E}-004$ & 7.925E-005 & 0.86 & $\begin{array}{c}0.5778 \\
\text { not significant }\end{array}$ \\
\hline Pure error & 2 & $1.847 \mathrm{E}-004$ & $9.233 \mathrm{E}-005$ & - & - \\
\hline Total & 14 & 0.74 & - & - & - \\
\hline
\end{tabular}


Table 5

ANOVA table for tool vibration

\begin{tabular}{|c|c|c|c|c|c|}
\hline Source & DOF & Square & Mean square & F-value & P-value \\
\hline Model & 9 & 187.21 & 20.80 & 14.13 & $0.0047^{*}$ \\
\hline $\mathrm{N}$ & 1 & 22.46 & 22.46 & 15.25 & 0.0113 \\
\hline $\mathrm{S}$ & 1 & 39.55 & 39.55 & 26.86 & 0.0035 \\
\hline $\mathrm{T}$ & 1 & 10.43 & 10.43 & 7.09 & 0.0448 \\
\hline $\mathrm{N}^{2}$ & 1 & 95.33 & 95.33 & 64.75 & 0.0005 \\
\hline $\mathrm{S}^{2}$ & 1 & $3.103 \mathrm{E}-003$ & $3.103 \mathrm{E}-003$ & $2.108 \mathrm{E}-003$ & 0.9652 \\
\hline$t^{2}$ & 1 & 10.57 & 10.57 & 7.18 & 0.0438 \\
\hline $\mathrm{N} * \mathrm{~S}$ & 1 & 11.39 & 11.39 & 7.74 & 0.0388 \\
\hline $\mathrm{N} * \mathrm{t}$ & 1 & 0.28 & 0.28 & 0.19 & 0.6831 \\
\hline $\mathrm{S} * \mathrm{t}$ & 1 & 0.71 & 0.71 & 0.48 & 0.5184 \\
\hline Res. Error & 5 & 7.36 & 1.47 & - & - \\
\hline Lack of fit & 3 & 7.31 & 2.44 & 90.33 & $0.0110^{*}$ \\
\hline Pure error & 2 & 0.054 & 0.027 & - & - \\
\hline Total & 14 & 194.57 & - & - & - \\
\hline $\mathrm{R}^{2}=0.9622, \mathrm{R}^{2}$ & 0.8941 & *Significant & & & \\
\hline
\end{tabular}

After elimination of the non significant terms, improved ANOVA analysis is shown in Table 6 and Table 7 , for surface roughness and tool vibration, respectively. It can be concluded that for both surface roughness and tool vibration, $\mathrm{R}^{2}$ and adjusted $\mathrm{R}^{2}$ values are more than $90 \%$. Lack of fit term is non significant for both the cases which was previously significant for tool vibration analysis. It proves backward elimination method is viable to improve the model performance.

Table 6

ANOVA table for surface roughness (after backward elimination)

\begin{tabular}{|c|c|c|c|c|c|}
\hline Source & DOF & Sum Square & Mean square & F-value & P-value \\
\hline Model & 6 & 0.74 & 0.12 & 1546.51 & $<0.0001^{*}$ \\
\hline $\mathrm{N}$ & 1 & 4.351E-004 & 4.351E-004 & 5.45 & 0.0479 \\
\hline $\mathrm{S}$ & 1 & 0.64 & 0.64 & 8050.85 & $<0.0001$ \\
\hline $\mathrm{T}$ & 1 & $4.005 \mathrm{E}-003$ & $4.005 \mathrm{E}-003$ & 50.15 & 0.0001 \\
\hline $\mathrm{N}^{2}$ & 1 & 0.039 & 0.039 & 484.15 & $<0.0001$ \\
\hline $\mathrm{S}^{2}$ & 1 & 0.028 & 0.028 & 345.25 & $<0.0001$ \\
\hline$t^{2}$ & 1 & 0.022 & 0.022 & 280.08 & $<0.0001$ \\
\hline Res. error & 8 & 6.389E-004 & $7.986 \mathrm{E}-005$ & - & - \\
\hline Lack of fit & 6 & $4.542 \mathrm{E}-004$ & $7.571 \mathrm{E}-005$ & 0.82 & $\begin{array}{c}0.6406 \\
\text { not significant }\end{array}$ \\
\hline Pure error & 2 & $1.847 \mathrm{E}-004$ & $9.233 \mathrm{E}-005$ & - & - \\
\hline Total & 14 & 0.74 & - & - & - \\
\hline $\mathrm{R}^{2}=0.9991, \mathrm{R}^{2}$ & 0.9985 & gnificant & & & \\
\hline
\end{tabular}

Table 7

ANOVA table for tool vibration (after backward elimination)

\begin{tabular}{|c|c|c|c|c|c|}
\hline Source & DOF & Sum Square & Mean square & F-value & P-value \\
\hline Model & 6 & 186.22 & 31.04 & 29.74 & $<0.0001$ significant \\
\hline $\mathrm{N}$ & 1 & 22.46 & 22.46 & 21.52 & 0.0017 \\
\hline $\mathrm{S}$ & 1 & 39.55 & 39.55 & 37.89 & 0.0003 \\
\hline $\mathrm{T}$ & 1 & 10.43 & 10.43 & 10.00 & 0.0134 \\
\hline $\mathrm{N}^{2}$ & 1 & 95.81 & 95.81 & 91.79 & $<0.0001$ \\
\hline $\mathrm{t}^{2}$ & 1 & 10.61 & 10.61 & 10.16 & 0.0128 \\
\hline $\mathrm{N}^{*} \mathrm{~S}$ & 1 & 11.39 & 11.39 & 10.92 & 0.0108 \\
\hline Res. Error & 8 & 8.35 & 1.04 & - & - \\
\hline Lack of fit & 6 & 8.30 & 1.38 & 51.28 & $\begin{array}{c}0.0693 \\
\text { Not Significant }\end{array}$ \\
\hline Pure error & 2 & 0.054 & 0.027 & - & - \\
\hline Total & 14 & 194.57 & - & - & - \\
\hline \multicolumn{6}{|c|}{$\mathrm{R}^{2}=0.9571, \mathrm{R}^{2}$ adjusted $=0.9249$} \\
\hline
\end{tabular}


After elimination of the non-significant terms from the model, the final regression equation for surface roughness and tool vibration are given by:

$$
\begin{aligned}
& \mathrm{R}_{\mathrm{a}}=-17.14417+0.053066 \times \mathrm{N}-0.018800 \times \mathrm{S}+4.89375 \times \mathrm{t}-4.09333 \mathrm{E}-005 \times \mathrm{N}^{2}+5.53067 \mathrm{E}-004 \times \mathrm{S}^{2}-7.78333 \times \mathrm{t}^{2}, \\
& \mathrm{~V}=-889.76191+2.77578 \times \mathrm{N}+1.93314 \times \mathrm{S}+112.8129 \times \mathrm{t}-2.70040 \mathrm{E}-003 \times \mathrm{N} \times \mathrm{S}-2.03154 \mathrm{E}-003 \times \mathrm{N}^{2}- \\
& 168.98615 \times \mathrm{t}^{2} .
\end{aligned}
$$

To predict tool vibration and surface roughness these developed regression models can be used. Fig. 4 and 5 depicts the predicted and actual values and it shows that patterns are obvious. Fig. 6 and 7 illustrates the normal probability of residuals. It reveals that all the residual points are falling in a straight line which means, the errors are normally distributed. This indicates that the developed regression model is acceptable under given experimental range.

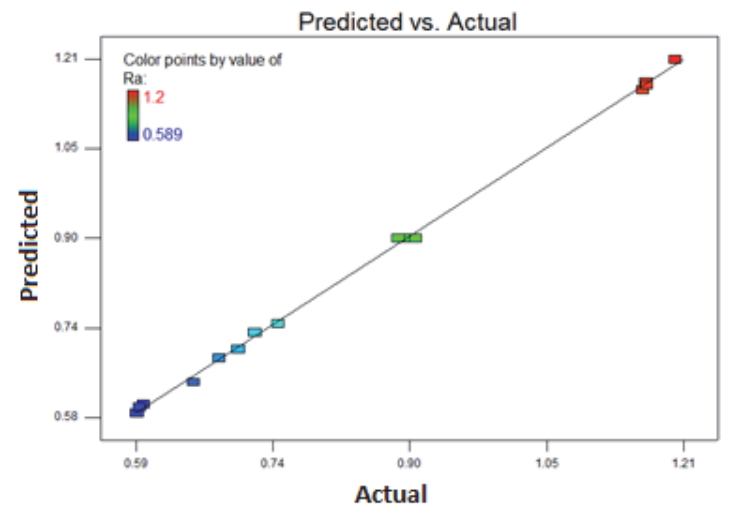

Fig. 4. Predicted vs. actual response plot of surface roughness

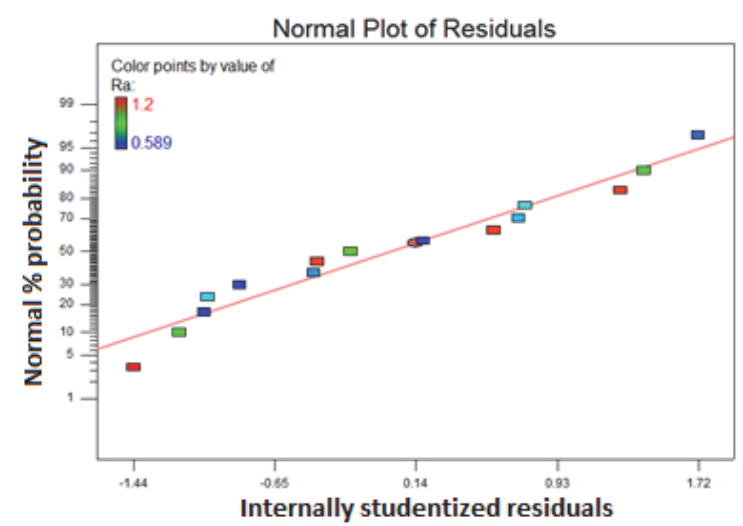

Fig. 6. Normal probability plot of residuals for surface roughness

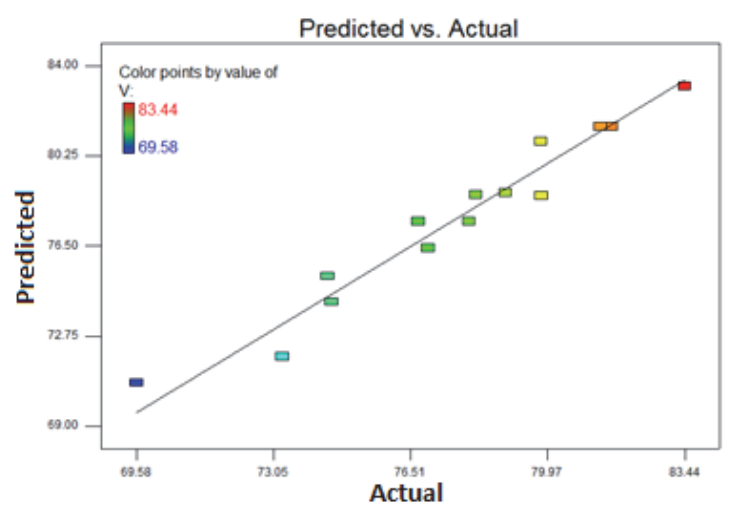

Fig. 5. Predicted vs. actual response plot of tool vibration

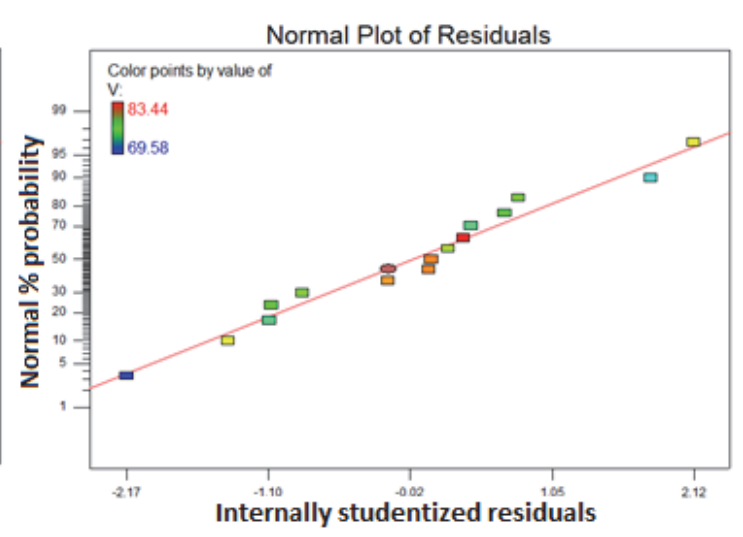

Fig. 7. Normal probability plot of residuals for tool vibration

3-D response surface plots are drawn based on the regression equations 7 and 8 for the better understanding of interaction effects of independent variables on responses. As every model comprises of three independent variables, one variable has been kept constant at its centre level for each plot.

Fig. 8 and Fig. 9 depict 3-D surface plot for surface roughness, whereas Fig. 10 and Fig. 11 represent 3D surface plot for tool vibration. Except the effect of feed rate for tool vibration all the independent variables show curvature trend for the responses and hence variation is non-linear. Fig. 8 and Fig. 9 are drawn on the basis of Eq. (7). It can be observed that surface roughness increases with increase in rotational speed, depth of cut and feed rate. However, the effect of rotational speed with surface 
roughness violates the general trends; vibration may be regarded as one of the cause for such violation at higher speeds. 3-D surface plots for tool vibration are drawn on the basis of Eq. (8). It can be concluded from the plots that tool vibration increases for all three input parameters.

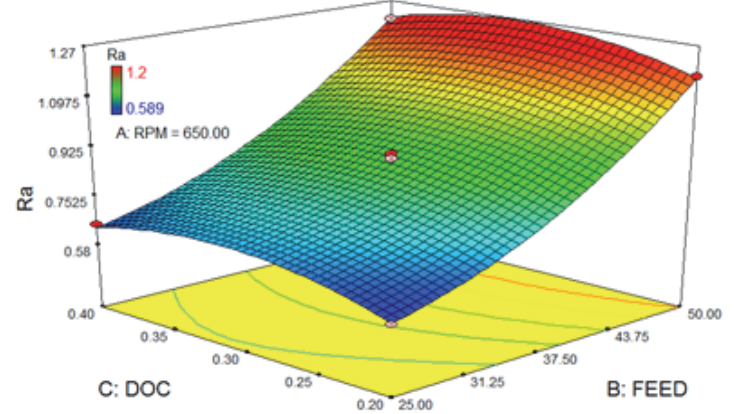

Fig. 8. Effect of depth of cut (t) and feed rate (s) on surface roughness (3-D plot)

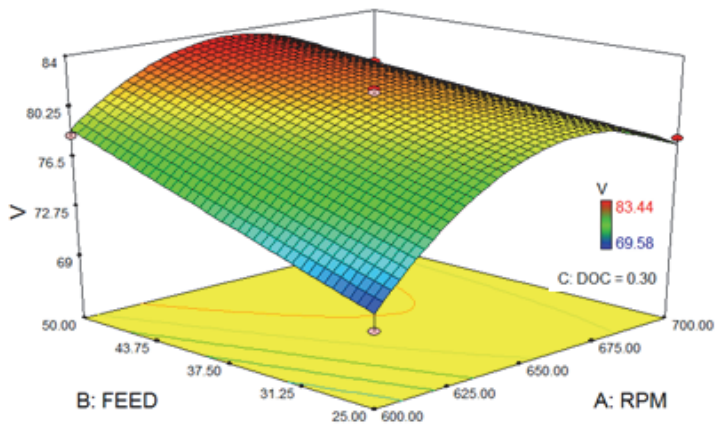

Fig. 10. Effect of spindle speed $(\mathrm{N})$ and feed rate (s) on tool vibration (3-D plot)

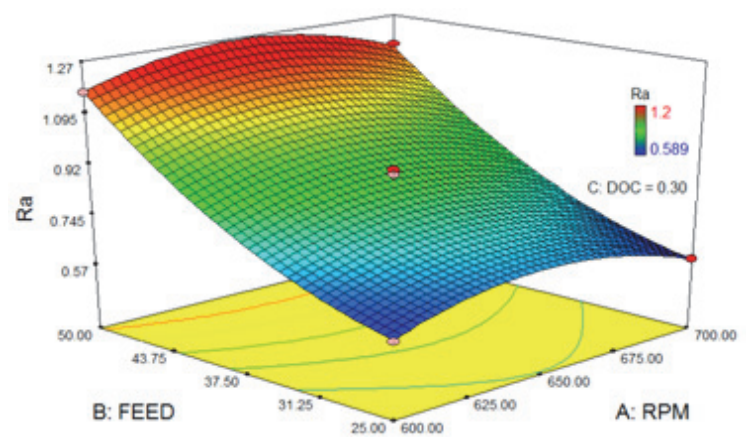

Fig. 9. Effect of feed rate (s) and spindle speed (N) on surface roughness (3-D plot)

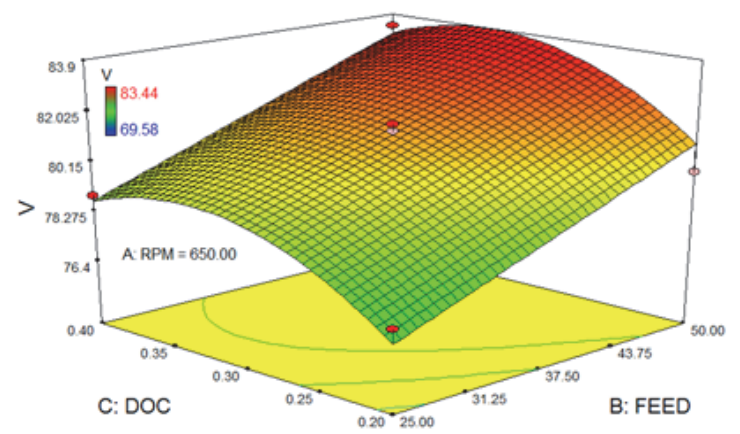

Fig. 11. Effect of feed rate (s) and depth of cut ( $t)$ on tool vibration (3-D plot)

\subsection{Multi objective optimization}

Initially, the experimental data of surface roughness and tool vibration, as shown in Table 3, are normalized. For normalization of all the responses, lower the better criteria have been implemented by using the Eq. (9), which is given as:

$$
\mathrm{X}_{\mathrm{i}}^{\times}(\mathrm{k})=\frac{\min X_{i}(k)}{X_{i}(k)},
$$

where, $\mathrm{i}=1,2, \ldots \ldots \ldots, \mathrm{m} ; \mathrm{k}=1,2, \ldots \ldots \ldots, \mathrm{n} . \mathrm{m}$ is the number of experimental runs and $\mathrm{n}$ is the number of quality characteristics. The normalized responses range is kept between 0 to 1 and these are presented in Table 8. After normalization the next step is to check the correlation between the responses. The Pearson's correlation coefficient for the responses is shown in Table 9. It can be observed that the coefficient is a non-zero value which indicates that the responses are correlated. To eliminate correlation between the responses, PCA has been applied using the MINITAB. The details of the PCA (Eigen value, eigen vector, accountability proportion) are shown in Table 10. Uncorrelated indexes broadly known as principal components $\left(\mathrm{P}_{1}, \mathrm{P}_{2}\right)$ are obtained from the correlated responses using the equation 5. To calculate MPI value accountability proportion (AP) has been used as individual weight of the principal components. The value is calculated using equation 6 and obtained MPI data are shown in Table 11. MPI value is treated as single objective function for optimization in order to minimize surface roughness and tool vibration. Higher MPI value gives better results, From the Table 11 it seems that optimum combination can be obtained nearer to the highest MPI value i.e. 1.1958. The factorial combination that maximizes MPI can be treated as optimal parametric combination or most favourable environment 
ensuring low surface roughness and tool vibration. This has been performed using main effect plot of mean for MPI as shown in Table 12 and Fig. 12.

The suggested optimum level from main effect plot for MPI is $N_{1} S_{1} t_{1}$. Table 13 shows the results of the confirmation experiments using the optimal machining parameters. From Table 13, it is clear that $\mathrm{R}_{\mathrm{a}}$ value is decreased from $0.893 \mu \mathrm{m}$ to $0.541 \mu \mathrm{m}$ and vibration value decreased from $80.579 \mathrm{db}$ to 70.392 $\mathrm{db}$. MPI value increased from 0.9362 to 1.227 from the initial setting. From Table 11, it is observed that highest MPI value is 1.1958 having combinations of spindle speed $600 \mathrm{rpm}$, feed $25 \mathrm{~mm} / \mathrm{min}$ and depth of cut $0.3 \mathrm{~mm}$ and responses $\mathrm{Ra}$ value $0.596 \mu \mathrm{m}$ and $\mathrm{V}$ value $69.58 \mathrm{db}$ which is higher than that of confirmation experiment shown in Table 12. As a whole, it is found that the multiple performance characteristics in the $\mathrm{CNC}$ turning process are improved through this study.

Table 8

Normalized responses for surface roughness and vibrations

\begin{tabular}{ccc}
\hline Sl. No. & Ra & V \\
\hline Ideal & 1.000 & 1.000 \\
$\mathbf{1}$ & 0.7864 & 0.9833 \\
$\mathbf{2}$ & 0.6508 & 0.9011 \\
$\mathbf{3}$ & 0.8366 & 1.0000 \\
$\mathbf{4}$ & 0.5047 & 0.9374 \\
$\mathbf{5}$ & 0.9020 & 0.9285 \\
$\mathbf{6}$ & 0.5064 & 0.9180 \\
$\mathbf{7}$ & 1.0000 & 0.9394 \\
$\mathbf{8}$ & 0.5043 & 0.9181 \\
$\mathbf{9}$ & 0.4908 & 0.8780 \\
$\mathbf{1 0}$ & 0.9883 & 1.0529 \\
$\mathbf{1 1}$ & 0.9949 & 0.9521 \\
$\mathbf{1 2}$ & 0.6596 & 0.8981 \\
$\mathbf{1 3}$ & 0.8636 & 0.9846 \\
$\mathbf{1 4}$ & 0.8147 & 0.9551 \\
$\mathbf{1 5}$ & 0.6648 & 0.8979 \\
\hline
\end{tabular}

Table 9

Correlation checking

\begin{tabular}{ccc}
\hline $\begin{array}{c}\text { Correlation between } \\
\text { responses }\end{array}$ & $\begin{array}{c}\text { Pearson correlation } \\
\text { coefficient }\end{array}$ & Comment \\
\hline Ra and $\mathbf{V}$ & 0.646 & Co-related \\
\hline
\end{tabular}

Table 10

Principal component analysis

\begin{tabular}{ccc}
\hline & $\boldsymbol{\Phi}_{\mathbf{1}}$ & $\boldsymbol{\Phi}_{\mathbf{2}}$ \\
\hline Eigen value & 1.6461 & 0.3539 \\
Eigen vector & $|0.707|$ & $\mid-0.707$ \\
AP & 0.707 & $0.707 \mid$ \\
CAP & 0.823 & 0.177 \\
\hline
\end{tabular}


Table 11

Principal components and MPI

\begin{tabular}{cccc}
\hline \multirow{2}{*}{ S1. N0. } & \multicolumn{2}{c}{ Individual principal components } & MPI \\
\cline { 2 - 3 } & $\mathrm{P}_{1}$ & $\mathrm{P}_{2}$ & 1.1637 \\
\hline Ideal & 1.414 & 0.000 & 1.0544 \\
1 & 1.2512 & 0.1392 & 0.9343 \\
2 & 1.0972 & 0.1769 & 1.0891 \\
3 & 1.2985 & 0.1155 & 0.8932 \\
4 & 1.0196 & 0.3059 & 1.0684 \\
5 & 1.2942 & 0.0187 & 0.8803 \\
6 & 1.0071 & 0.2909 & 1.1209 \\
7 & 1.3712 & -0.0428 & 0.8794 \\
8 & 1.0056 & 0.2926 & 0.8449 \\
9 & 0.9678 & 0.2737 & 1.1958 \\
10 & 1.4431 & 0.0457 & 1.1276 \\
11 & 1.3766 & -0.0303 & 0.9362 \\
12 & 1.1012 & 0.1686 & 1.0905 \\
13 & 1.3067 & 0.0855 & 1.0474 \\
14 & 1.2513 & 0.0993 & 0.9384 \\
\hline
\end{tabular}

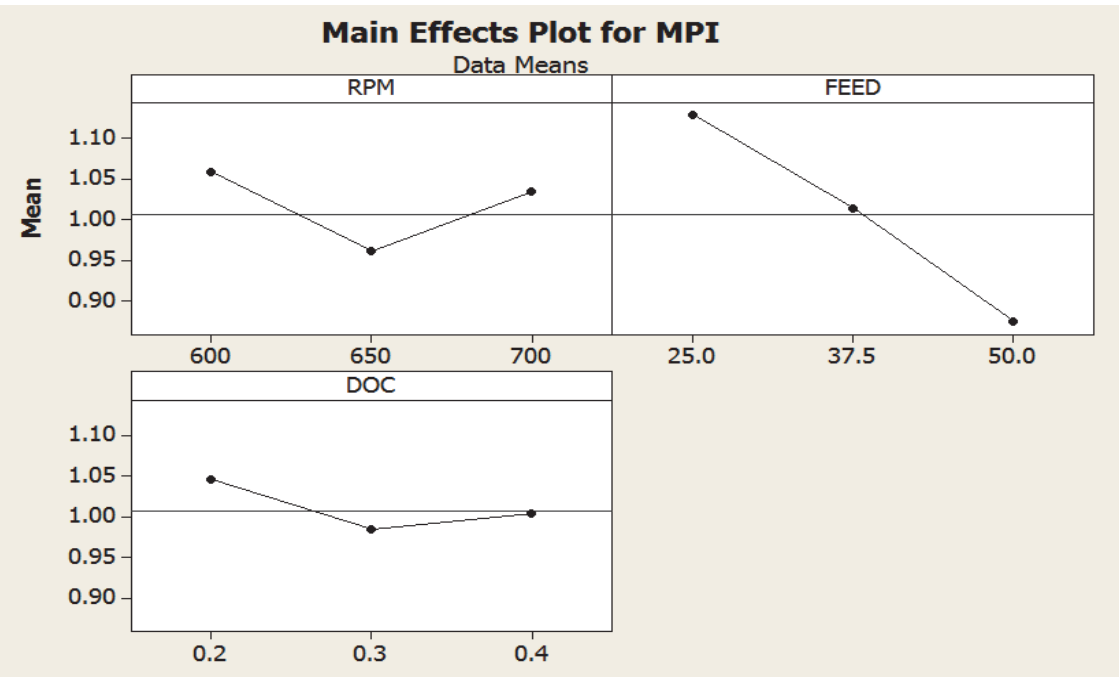

Fig. 12. Main effects plot for MPI

Table 12

Analysis of means of MPI

\begin{tabular}{cccc}
\hline Level & Spindle speed(N) & Feed rate(s) & Depth of cut(t) \\
\hline $\mathbf{1}$ & $\mathbf{1 . 0 5 8 1}$ & $\mathbf{1 . 1 2 8 1}$ & $\mathbf{1 . 0 4 6 6}$ \\
$\mathbf{2}$ & 0.9613 & 1.0129 & 0.9855 \\
$\mathbf{3}$ & 1.0347 & 0.8744 & 1.0037 \\
Delta & 0.0968 & 0.2537 & 0.0611 \\
Rank & 2 & 1 & 3 \\
\hline
\end{tabular}


Table 13

Comparison of machining performances using initial and optimal cutting parameters

\begin{tabular}{ccc}
\hline & $\begin{array}{c}\text { Initial cutting } \\
\text { parameters }\end{array}$ & $\begin{array}{c}\text { optimum cutting } \\
\text { parameters }\end{array}$ \\
\hline Spindle speed, Feed rate $\&$ & $650 \mathrm{RPM}, 37.5 \mathrm{~mm} / \mathrm{min}$, & $600 \mathrm{RPM}, 25 \mathrm{~mm} / \mathrm{min}$, \\
Depth of cut & $0.3 \mathrm{~mm}$ & $0.2 \mathrm{~mm}$ \\
$\mathbf{R}_{\mathbf{a}}$ value $(\boldsymbol{\mu m})$ & 0.893 & 0.541 \\
V value $(\mathbf{d b})$ & 81.579 & 70.392 \\
MPI value & 0.9362 & 1.227 \\
MPI value increased by $\mathbf{0 . 2 9 0 8}$ & & \\
\hline
\end{tabular}

\section{Conclusions}

The aforementioned study presented an integrated application of RSM and WPCA technique for the modelling and optimization of process parameters to achieve good surface finish and lower tool vibration in CNC turning process. The outcomes of the study can be summarised as:

- ANOVA analysis reveals that feed rate and second order term of spindle speed is most influencing parameter for surface roughness and tool vibration respectively.

- It can be observed that the interaction effects are not significant for the model in case of surface roughness however the interaction effect of spindle speed and feed are significant in case of tool vibration.

- $3 \mathrm{D}$ surface plots of the responses vs. the process parameters indicate that the interaction effects exist. The combined effect of spindle speed and feed rate on surface roughness is however found to be much less than those of a) spindle speed and depth of cut and b) feed rate and depth of cut. Also, the combined effect of a) spindle speed and depth of cut and b) feed rate and depth of cut on vibration is found to be of lesser degree than those of spindle speed and feed rate.

- The response surface methodology used in the recent study has been proven as an effective tool for the analysis of the CNC turning process.

- Application of WPCA is an improved multi output optimisation technique by considering AP as individual weight of the principal components which merely fulfil the weightage criteria for the researchers. MPI value has been regarded as the index for single objective optimisation.

- From the main effect plot for MPI, optimal conditions for both the responses are: spindle speed $600 \mathrm{RPM}$, feed rate $25 \mathrm{~mm} / \mathrm{min}$, depth of cut $0.2 \mathrm{~mm}$.

- Confirmatory experiment has been performed at optimum condition and observed surface roughness is $0.541 \mu \mathrm{m}$ and tool vibration is $70.392 \mathrm{db}$. MPI value is increased nby 0.2908 from the initial setting which adds a strong acceptance of WPCA technique.

- The discussed approach can be suggested for modelling and multi output optimisation of various machining processes.

\section{References}

Asiltürk, I., \& Neşeli, S. (2012). Multi response optimisation of CNC turning parameters via Taguchi method-based response surface analysis. Measurement, 45(4), 785-794.

Datta, S., Nandi, G., Bandyopadhyay, A., \& Pal, P. K. (2009). Application of PCA-based hybrid Taguchi method for correlated multicriteria optimization of submerged arc weld: a case study. The International Journal of Advanced Manufacturing Technology, 45(3-4), 276-286.

Feng, C. X. (2001). An experimental study of the impact of turning parameters on surface roughness. In Proceedings of the industrial engineering research conference (Vol. 2036).

Gupta, A., Singh, H., \& Aggarwal, A. (2011). Taguchi-fuzzy multi output optimization (MOO) in high speed CNC turning of AISI P-20 tool steel. Expert Systems with Applications, 38(6), 6822-6828. 
Kirby, E. D., Zhang, Z., \& Chen, J. C. (2004). Development of an accelerometer-based surface roughness prediction system in turning operations using multiple regression techniques. Journal of Industrial Technology, 20(4), 1-8.

Knight, W. A., \& Boothroyd, G. (2005). Fundamentals of metal machining and machine tools (Vol. 198). CRC Press.

Liao, H. C. (2006). Multi-response optimization using weighted principal component. The International Journal of Advanced Manufacturing Technology, 27(7-8), 720-725.

Makadia, A. J., \& Nanavati, J. I. (2013). Optimisation of machining parameters for turning operations based on response surface methodology. Measurement, 46(4), 1521-1529.

Montgomery, D. C. (1997) Design and analysis of experiments, $4^{\text {th }}$ ed., John wiley \& Sons Inc., New York.

Phadke, M. S. (1995). Quality engineering using robust design. Prentice Hall PTR.

Palanikumar, K. (2010). Modeling and analysis of delamination factor and surface roughness in drilling GFRP composites. Materials and Manufacturing Processes, 25(10), 1059-1067.

Risbood, K. A., Dixit, U. S., \& Sahasrabudhe, A. D. (2003). Prediction of surface roughness and dimensional deviation by measuring cutting forces and vibrations in turning process. Journal of Materials Processing Technology, 132(1), 203-214.

Roy, P., Sarangi, S. K., Ghosh, A., \& Chattopadhyay, A. K. (2009). Machinability study of pure aluminium and $\mathrm{Al}-12 \% \mathrm{Si}$ alloys against uncoated and coated carbide inserts. International Journal of Refractory Metals and Hard Materials, 27(3), 535-544.

Rudrapati, R., Pal, P. K., \& Bandyopadhyay, A. (2016). Modeling and optimization of machining parameters in cylindrical grinding process. The International Journal of Advanced Manufacturing Technology, 82(9-12), 2167-2182.

Routara, B. C., Mohanty, S. D., Datta, S., Bandyopadhyay, A., \& Mahapatra, S. S. (2010). Combined quality loss (CQL) concept in WPCA-based Taguchi philosophy for optimization of multiple surface quality characteristics of UNS C34000 brass in cylindrical grinding. The International Journal of Advanced Manufacturing Technology, 51(1-4), 135-143.

Routara, B. C., Sahoo, A. K., Parida, A. K., \& Padhi, P. C. (2012). Response surface methodology and genetic algorithm used to optimize the cutting condition for surface roughness parameters in CNC turning. Procedia Engineering, 38, 1893-1904.

Senthilkumar, N., Tamizharasan, T., \& Anandakrishnan, V. (2014). Experimental investigation and performance analysis of cemented carbide inserts of different geometries using Taguchi based grey relational analysis. Measurement, 58, 520-536.

Siddhpura, M., \& Paurobally, R. (2012). A review of chatter vibration research in turning. International Journal of Machine tools and manufacture, 61, 27-47.

$\mathrm{Su}, \mathrm{C} . \mathrm{T} .$, \& Tong, L. I. (1997). Multi-response robust design by principal component analysis. Total Quality Management, 8(6), 409-416.

Tobias, S. A. (1961). Machine tool vibration research. International Journal of Machine Tool Design and Research, 1(1), 1-14.

Wang, Z., Meng, H., \& Fu, J. (2010). Novel method for evaluating surface roughness by grey dynamic filtering. Measurement, 43(1), 78-82.

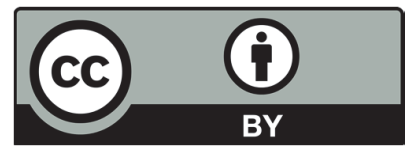

(C) 2016 by the authors; licensee Growing Science, Canada. This is an open access article distributed under the terms and conditions of the Creative Commons Attribution (CCBY) license (http://creativecommons.org/licenses/by/4.0/). 